\title{
المناخ الأسري التربوي للمتفوقين دراسيا
}

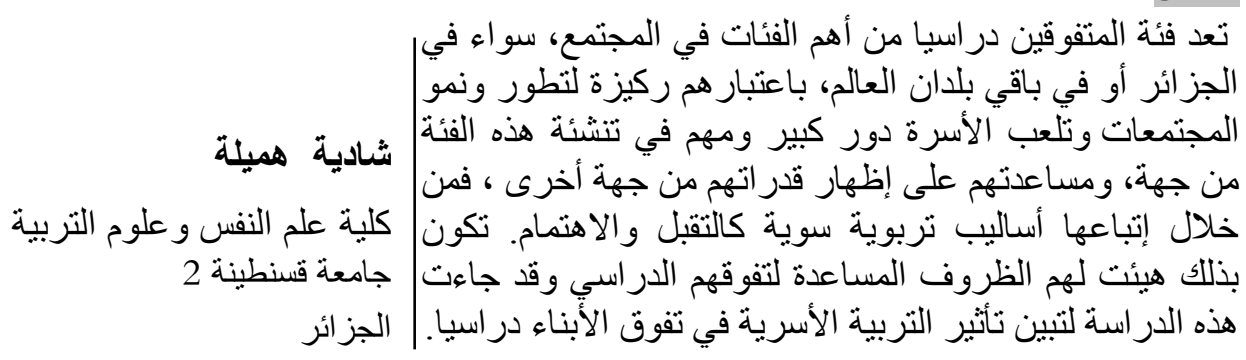

\section{مقدمة}

مـهـتم المجتمع و يقدر تميز أفراده في أي

ميدان من النشاط الإنساني، ويندرج

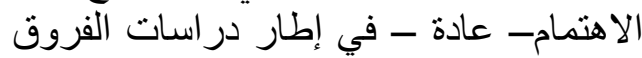

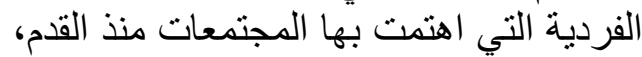

إذا أهتم بها في اختيار الموظفين الألفاء في

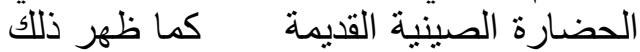

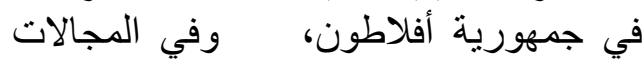

العسكرية والتربوية في المجنونة فئمعات الحديثة.

وأخذ الأمر بعدا علميا في الدراسات النفسية

في إطار ما يعرف بحركة القياس فئ القراس العقلي

الذي ظهر بقوة في القرن العشرين في

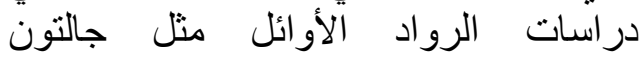

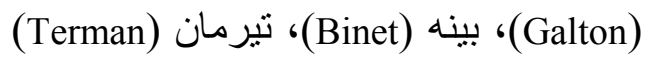

\section{Résumé}

La présente étude a pour objet la catégorie des surdoués et le rôle de la

وقد أصبح النظام التعليمي في عصر التقام famille dans son émergence. Il s'agit و التكنولوجيا يهتم بالفئات الخاصة الفئ خاصة فئة الفئة plus exactement de déterminer les المتفوقين، حيث اهتم علماء النفس الفات الناء modes éducatifs familiaux favorables à la formation de l'excellence scolaire. 
والتربية بدراسة هذه الفئة باعتبار ها قاعدة أساسية وضمانة لنطور الأمم والمجتمعات ونمو ها في الميادين المختلفة.

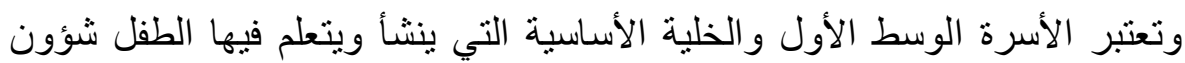

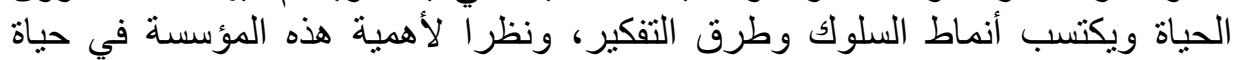

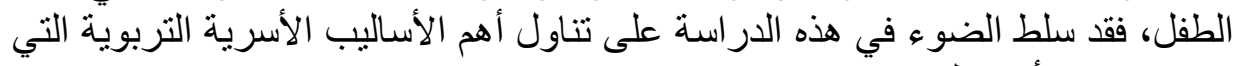
تحقق تفوق الأبناء الدر اسي.

\section{1- مشكلة الدراسة وأسئلتها :}

تتبع الأسرة في تربية أبنائها استراتيجيات أو أساليب تربوية معينة، أثبتت عدة

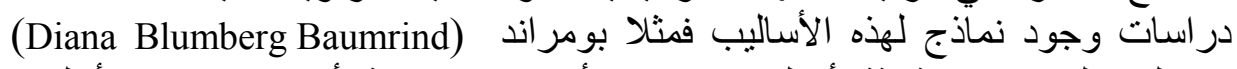

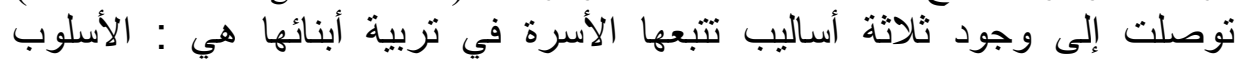

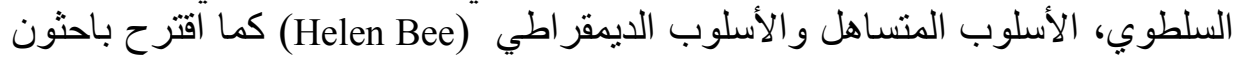

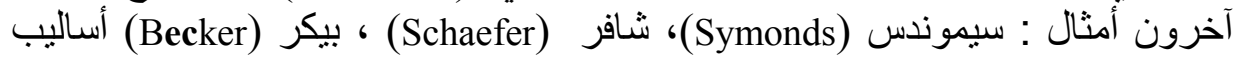

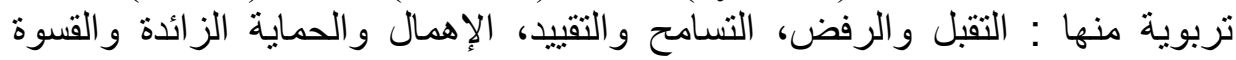
و التشجيع ...الخ. ولذلك نحاول من خلال هذه الدراسة معرفة أي الأساليب السائدة عند أسر المتفوقين، وذلك من خلال الإجابة عن الأسئلة الآتية:

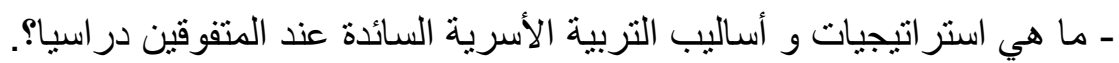

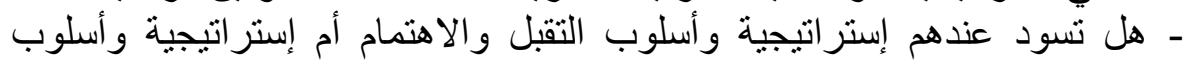

القسوة والإهمال ؟ تصو

- ما هي خصائص أسر المتفوقين ؟.

2- 2 - 2 أهداف الدراسة :

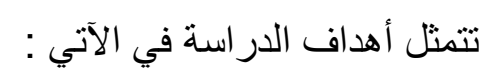

ـ التعرف على الإستر اتيجية أو أسلوب التربية السائد عند المتفوقين.

ـ التعرف على خصائص أسر المبر المتفوقين.

ـ الكثف عن دلالة الفروق بين المتفوقين والعادين العنين في الإستراتيجية الأسرية

$$
\text { التربوية. }
$$


3- - 3 - 3 أهمية الدراسة:

تفيد الأسرة عن الإستراتيجية أو الأسلوب التربوي الأمثل الذي يجعل أبنائها

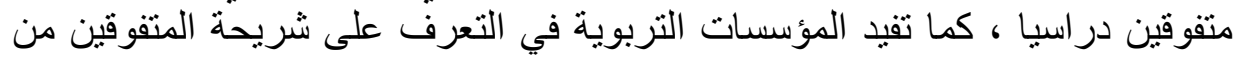
خلال معرفة سمات وخصائص شخصيتهم وكيفية تعاملهم مع الآخرين. 4- حدود الدراسة :

ـ الحد الزمني: امتدت مدة الدراسة من أكتوبر 2009 إلى نوفمبر 2010.

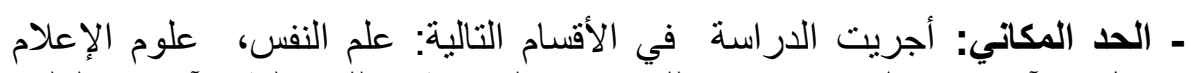

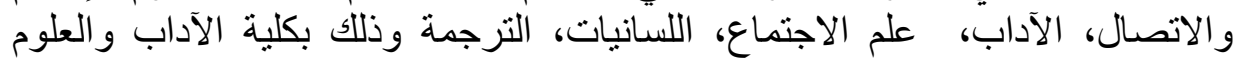
الإنسانية و الاجتماعية - البوني - علابة الإدابة

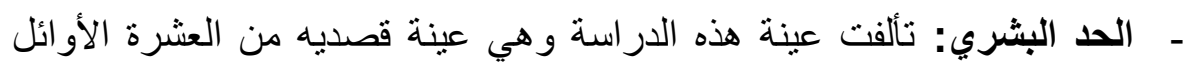

للسنة الثالثة ذكورا و إناثا من الأقسام المذكورة سابنة الثرانة

5- مصطلحات الدراسة:

- الإستراتيجية (Stratégie): نمط من الأفعال والتصرفات التي تستخدم لتحقيق

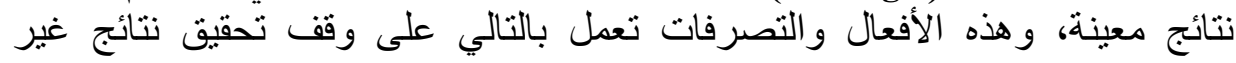
مرغوب فيها" (مجدي عزيز إبر اهيم، 2004، 216 216).

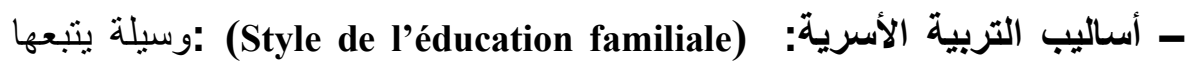

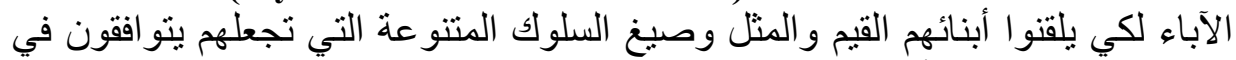

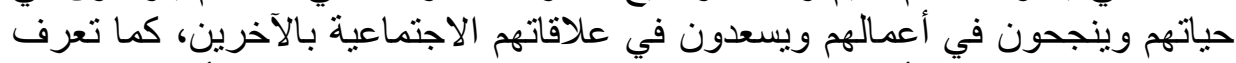

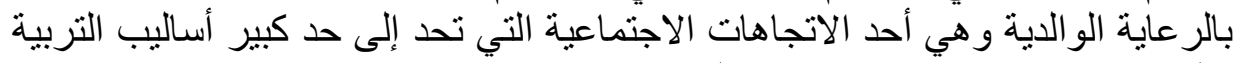
و التطبيع الاجتماعي". (يوسف الوالية عبد الفتاح محمد، 1990، 147).

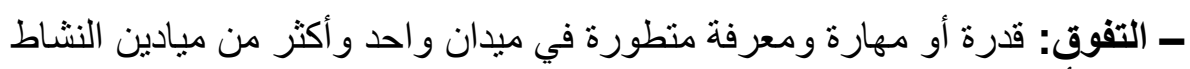

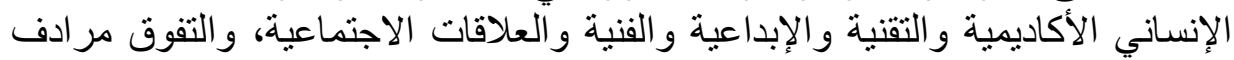

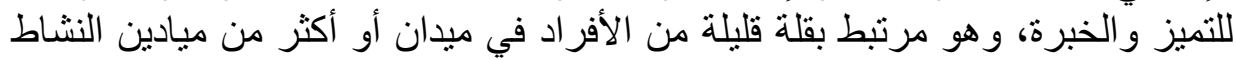

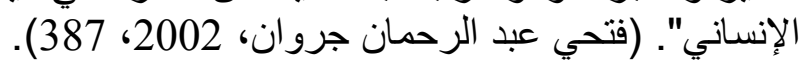
وقد اعتمد بعض الباحثين على بعض المحكات لتعريف التفوق، وأهمها: الذكاء

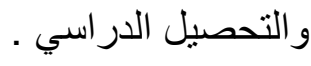

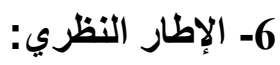

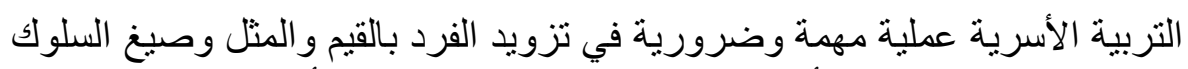

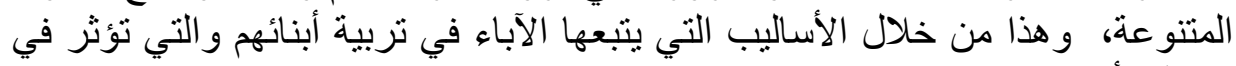
نفسية الأبناء.

1-6- بعض النماذج من أساليب التربية الأسرية: 
في مجال الدر اسات الغربية هناك بعض النماذج نذكر منها:

1

صنف سيموندس (1939) سلوك الو الدين مع الأبناء على أساس بعدين هما:

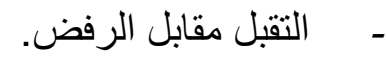

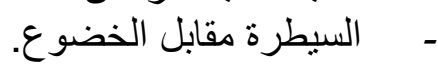

و هي أبعاد متصلة تشير إلى قطبين. (زكريا أحمد الثربيني، يسرية صادق، 2000،

2 - نموذج إيرال شايفر

وتوصل إلى وجود بعدين أساسيين لسلوك الآباء و الأمهات مهما:

الاستقلال مقابل الضبط -

وقد ذكر شايفر هذان البعدان بمسميات أخرى على النحو التالي:

- - - التقبل مقابل مقابل التقفيد. (محمود فتحي عكاثة، دس، 192).

ثم ظهر مقياس شايفر في صورته الأخيرة سنة 1965 ويحتوي على ثلاثة أبعاد

- - مالتقبل مقابل الرفض

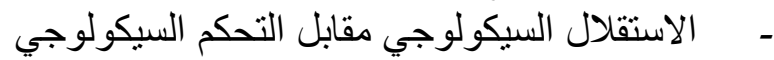

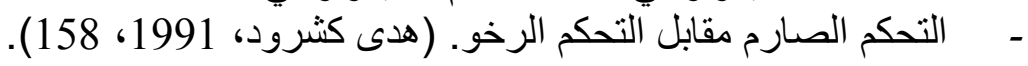

3 - نموذج بيكر (Becker) : عرض بيكر (1964) نموذجا موضحا فيه الأبعاد

التي يمكن أن ينتظم فيها أسلوب الو الدين في تربية الأبناء وهي:

- - - - الحب أو الدفء العاطفي مقابل العداء

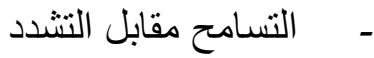

- - الاندماج الانفعالي (القلق) مقابل الابتعاد الهادئ. (محمود فتحي عكاشة، دس،

أما في مجال الدراسات العربية نجد:

ناهد رمزي (1976) توصلت من خلال در استها إلى ثلاثة أبعاد هي: 


$$
\text { - }
$$

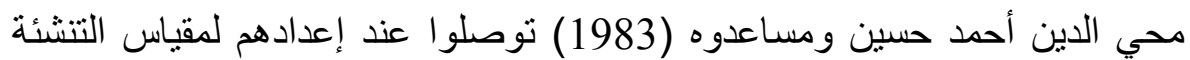
الأسرية ومن خلال التحليل العاملي أن هنالك أبعاد ثناثة هي:

$$
\text { - }
$$

يلاحظ أنه هناك اختلاف في نماذج أساليب التربية الأسرية التي توصل إليها

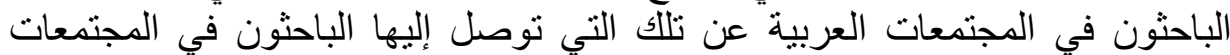

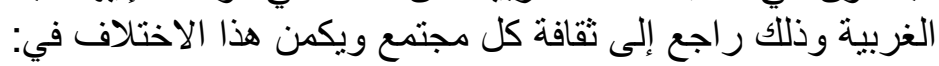

- - - مسمية الأبعاد للتربية الأسرية.

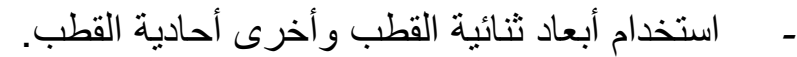
- - منفت الأبعاد إلى أساليب سوية وأخرى غير سوية.

\section{6-6-العوامل المؤثرة في أساليب التربية الأسرية:}

- المستوى الثقافي والاجتماعي للوالدين: هنالك ارتباط بين درجة تعلم الأبوين

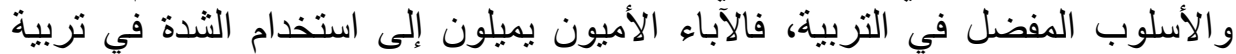
الأطفال، بينما الآباء المتعلمون يميلون إلى استخدام التشجيع، والحاء الحال كذللك بالنسبة

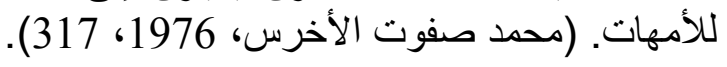

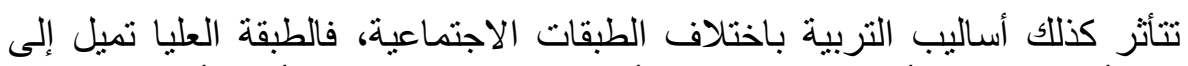

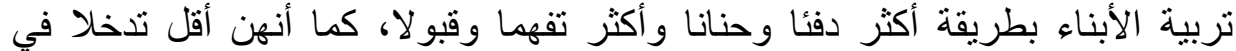
شؤونهم، (سيد محمد الطواب، 1998، 297) و وأما الطبقة المتوسطة تستخدم أسلوب

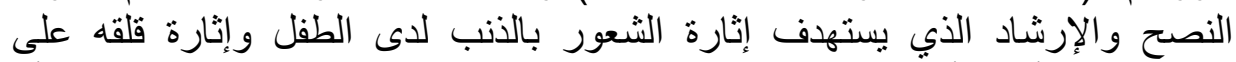

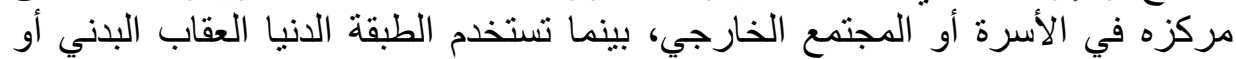
التهديد به. (محمد عماد الدين إسماعيل وآخرون، 1974، 47).

ـ القيم الدينية والخلقية: إذ نجد الأسر المحافظة والمتدينة تميل إلى ترسيخ قيم

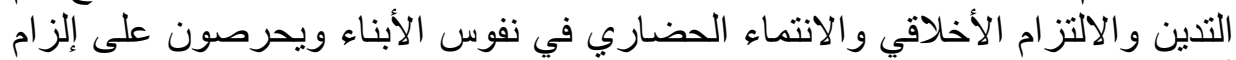

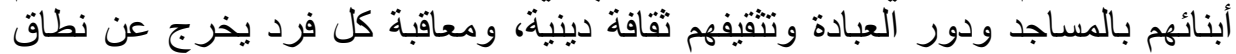
العادات والتقاليد الدينية، في حين نجد الأسر التي تميل إلى تقليد كل سلوك دلى جديد فيد في في

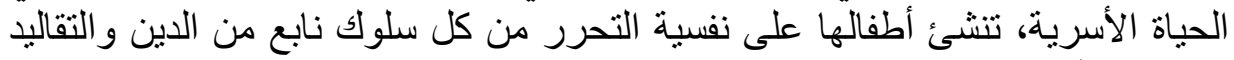

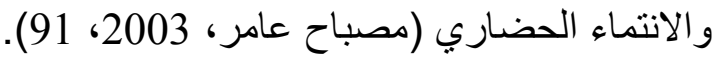


ـ تركيب الأسرة: تختلف أساليب التربية في الأسرة الممتدة عنها في الأسرة النووية،

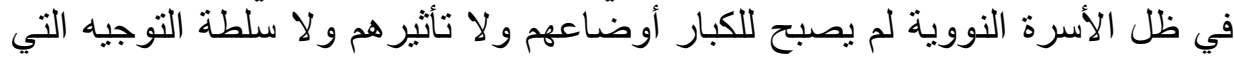

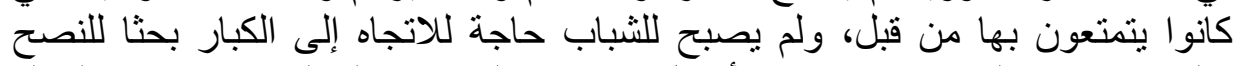

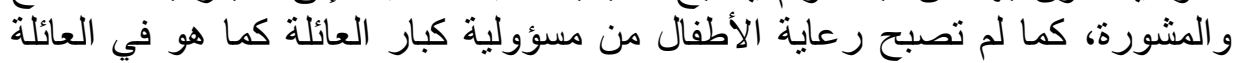

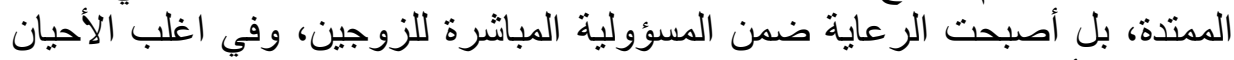

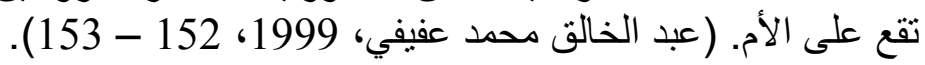

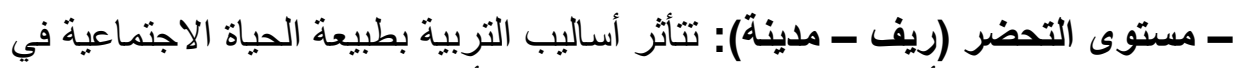

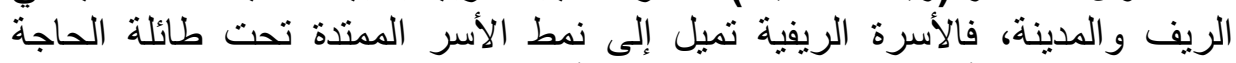

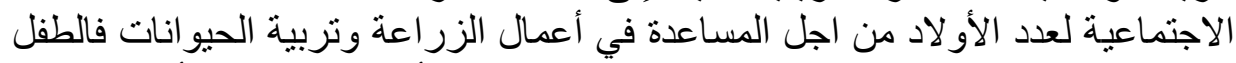

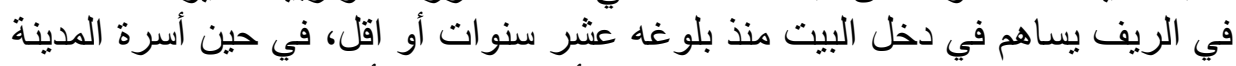

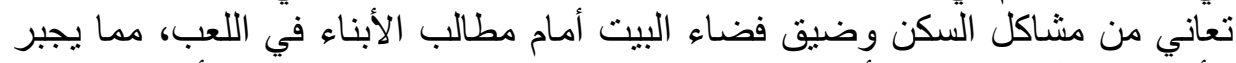

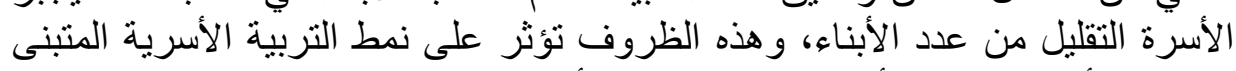

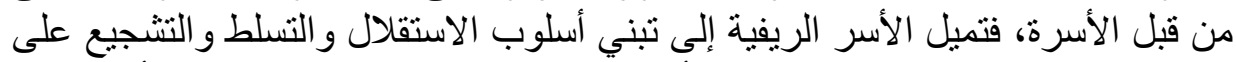

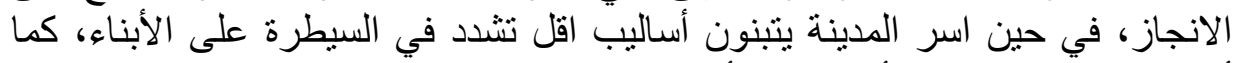

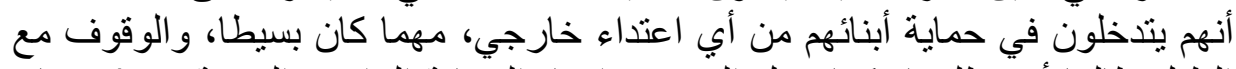

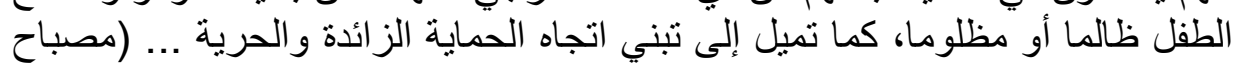

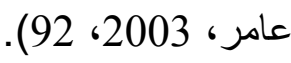

ـ حجم الأسرة: تتأثر أساليب التربية بعامل حجم الأسرة فتناقص حجم الأسرة يعمل فئل

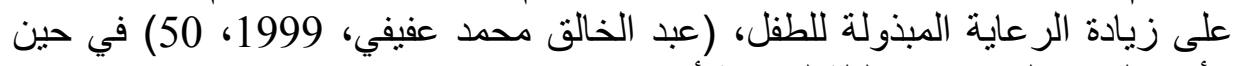
الأسر الكبيرة لهم فرص قليلة لمر اقبة أو لادهم.

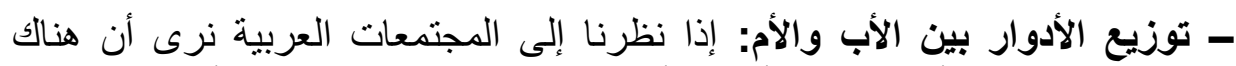

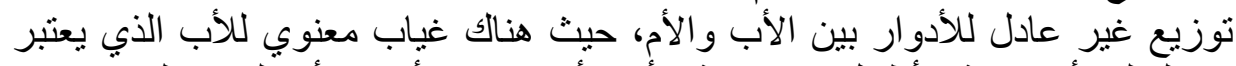

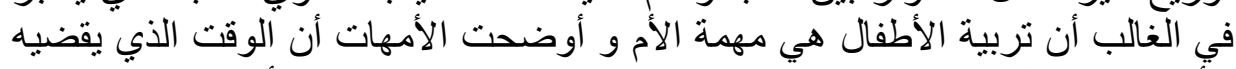

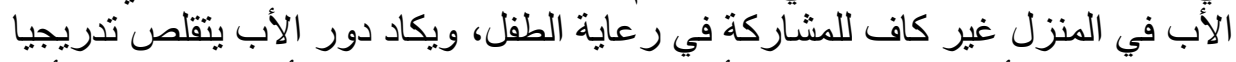

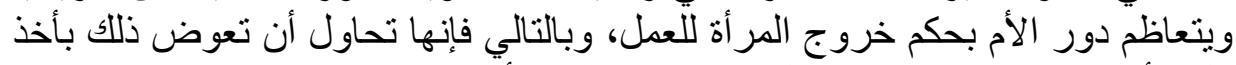

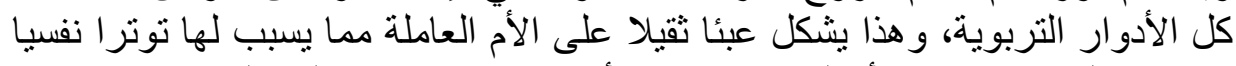

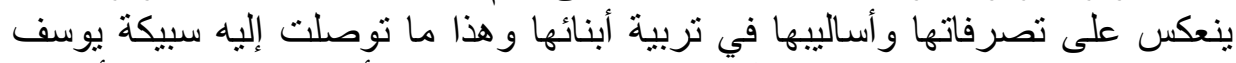

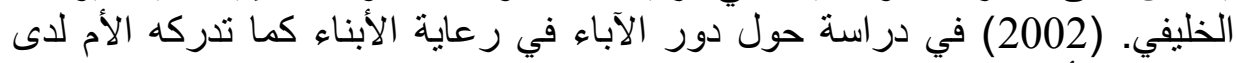

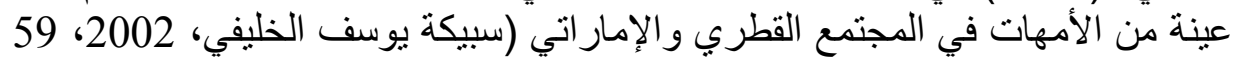

ـ جنس الطقل: يوجد تمييز في الأسر الجزائرية بين الذكور و الإناث حيث يفضلون

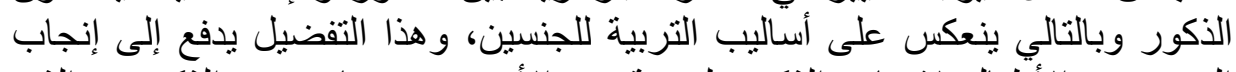

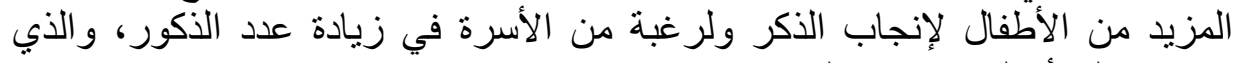

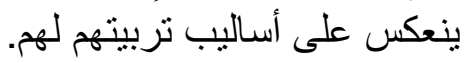




\section{أثر أساليب التربية على سلوك الطفل:}

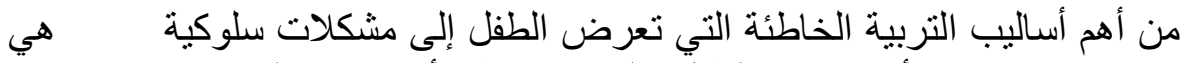

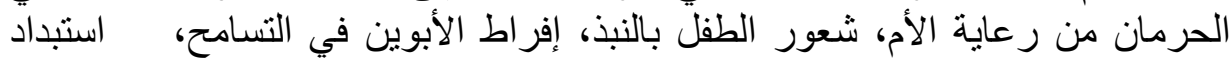

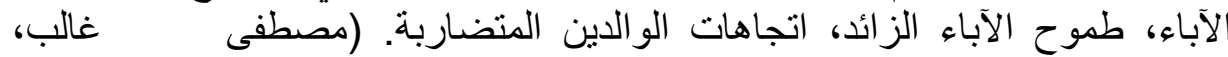

يرى بول هنري موسن (P.H. Mussen) أن أسلوب عدم الاتساق (التذبذب) يؤدي

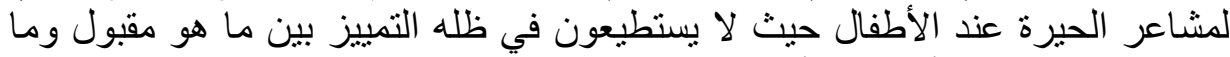

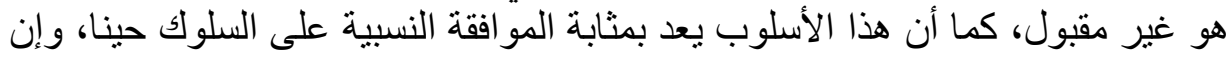

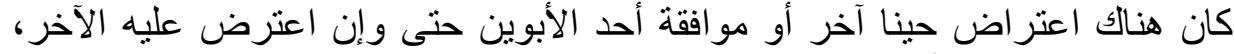

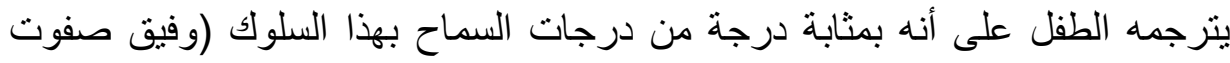

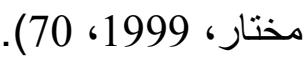

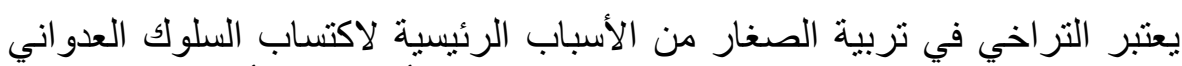

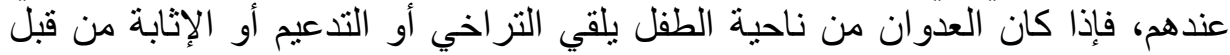

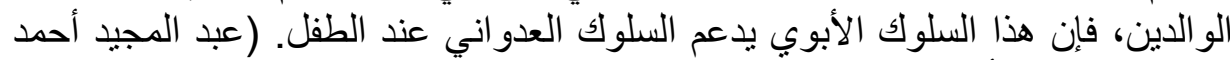

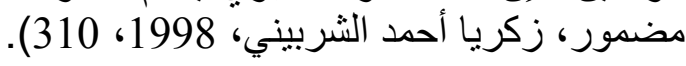

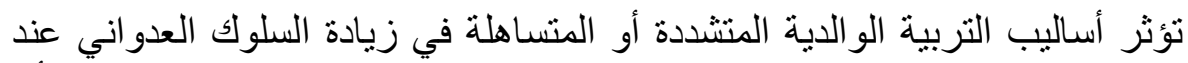

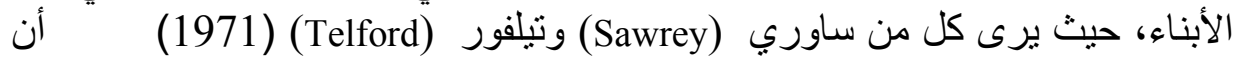

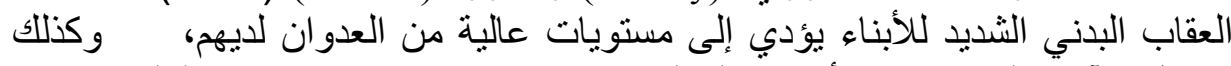

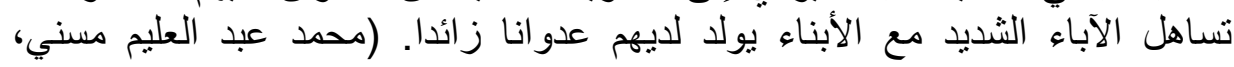
.99 1989

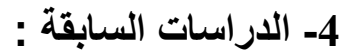

هناك دراسات عديدة تناولت بعض جوانب موضوع الدراسة منها الجزائرية و العربية والأجنبية منها:

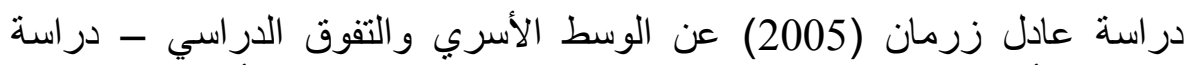
ميدانية على أسر التلاميذ المتفوقين في الطور الثاني الثاني من التعليم الأساسي بقسني التطينة حيث توصل الى النقاط التالية :

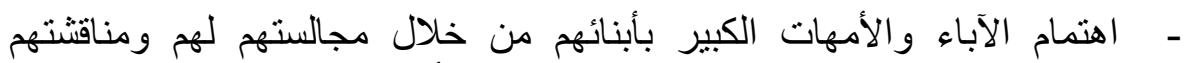

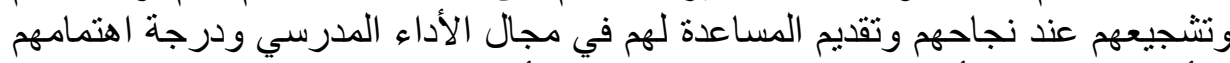
بالأداء المدرسي للأبناء كل هذا يؤدي إلى تفوق الأبناء الدراسي.

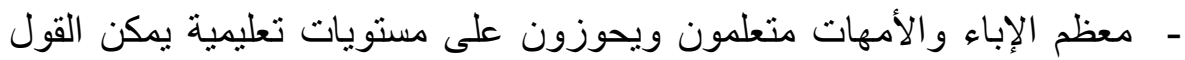
بأنها أعلى من المتوسط، وهو مؤشر بالغ الأبه ونهية. 
كما بينت دراسة خالد الطحان (1977) التي تناولت العلاقة بين التفوق وأساليب

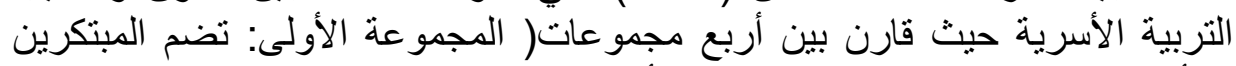

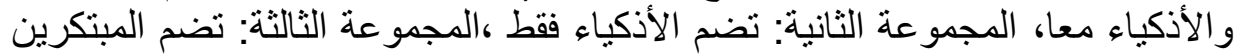
فقط ،المجموعة الرابعة: تضم العاديين من حيث الذكاء والقدة القدرة على التفكير ألابتكاري)

ـ أفر اد المجموعة الأولى كانو النعمون بتنشئة والدية تتسم بالتشجيع على الاستقلال

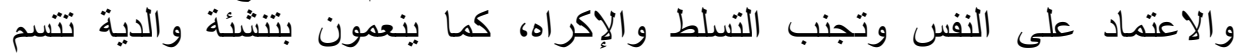

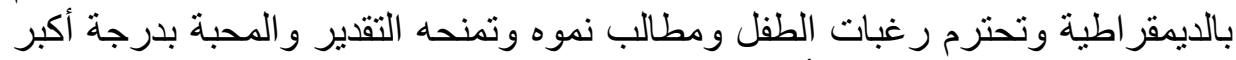

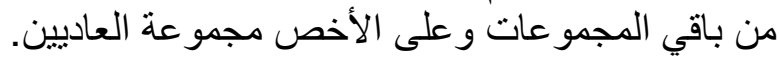

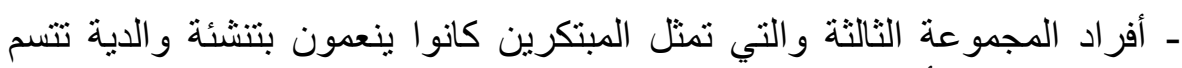

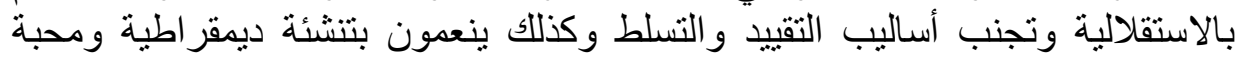
والدية بدرجة أفضل من مجمو عة العاديين.

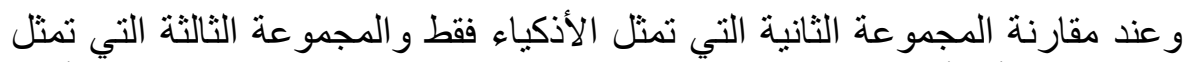

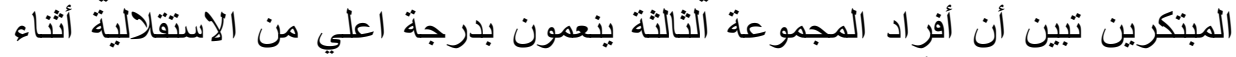

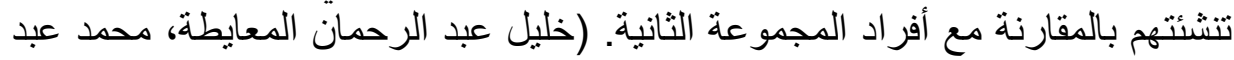

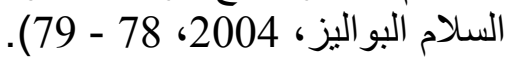

وتوصل رو (1953) في دراسته التي كان هدفه منها التعرف على أساليب التربية الأسرية للمتفوقين إلى :

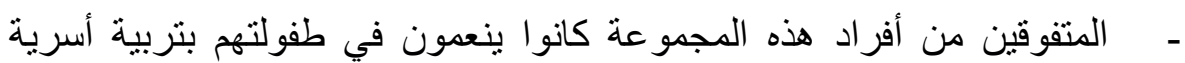
تتسم بالحرية ولا تلجأ إلى العقاب و القسوة.

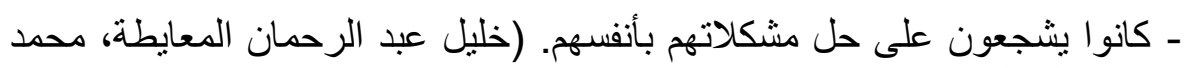
عبد السلام البو اليز، بـون 2004، 144).

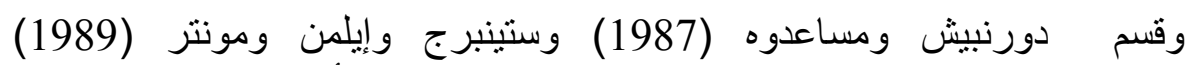
وكروكنبرج وليتمن (1990) ولمبورن ومساعدوه (1991) الأسر في دراساتهم إلى ونى ثلاثة أقسام هي : ت اكنرج

- - الأسر التي تستعمل الأسلوب السلطوي في تربية الأبناء تكون نتائج أبنائها

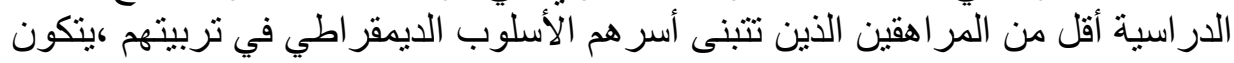

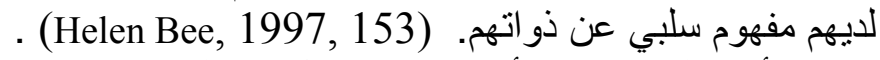
ـ الأسر التي تتبنى الأسلوب المنساهل في التربية تكون نسبة نجاح أبنائهم قليلة في

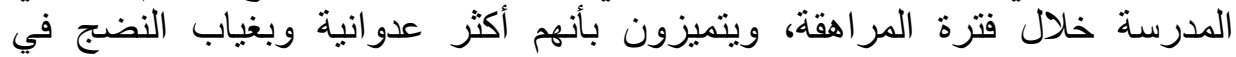

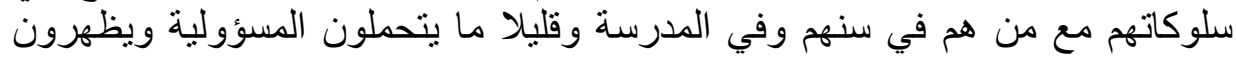

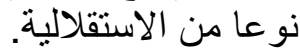




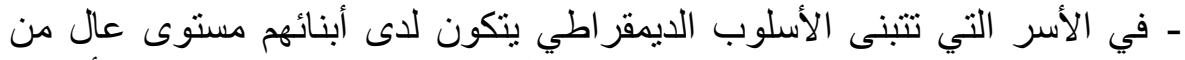

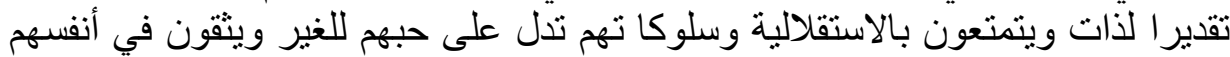

ونتائجهم المدرسية ممتازة. (Helene Bee, 1997, 155)

$$
\text { التعليق على الدراسات السابقة: }
$$

1. الكالك اتفاق على أن الأسر قد تتبنى الأسلوب السلطوي أو الأسلوب

$$
\text { المتساهل أو الأسلوب الديمقر اطي }
$$

2. ت تناولت الدر اسات كل مر احل النمو من الطفولة إلى الثيخوخة .

3. اغلب الدر اسات كانت تأخذ رأي الآباء دون الأبناء .

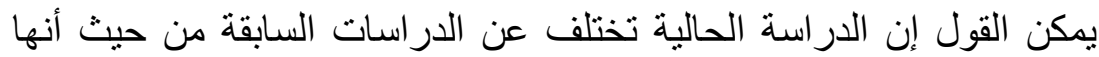

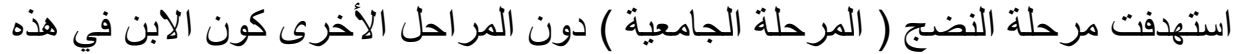

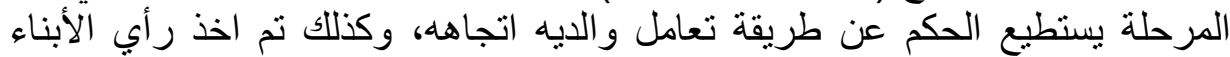

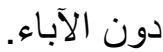

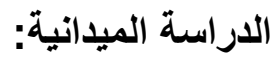

\section{1}

راعينا في هذه الدراسة اتباع المنهج الوصفي نظر التناسبه مع هدف الدئ الدراسة فهو

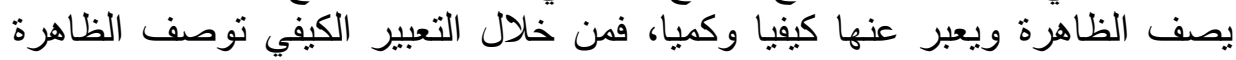

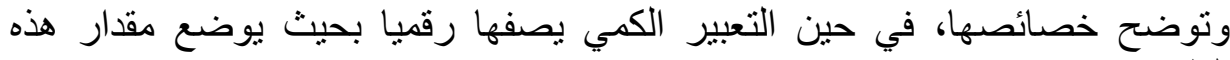

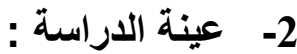

تألفت عينة هذه الدراسة وهي عينة قصدية من العشرة الأوائل للسنة الثالثة ذكورا

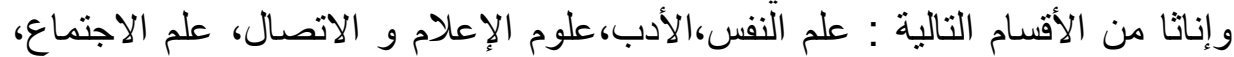

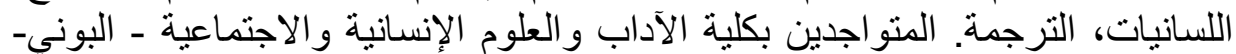

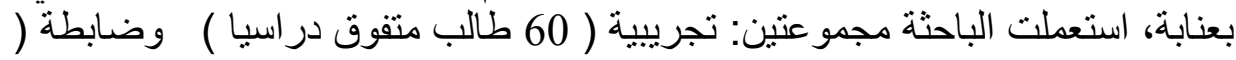

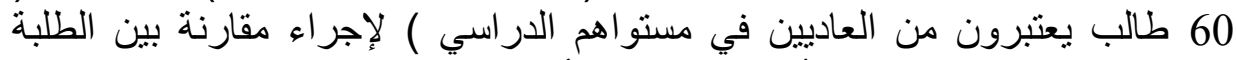
المتفوقين و الطلبة العاديين في أساليب التربية الأسرية.

$$
\text { 3- أدوات الدراسة : }
$$

استخدمت الباحثة الاستمارة بعد الاطلاع على مجموعة من الدراسات التي اهتمت

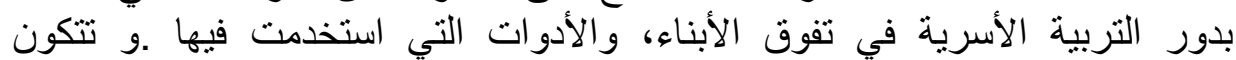
الاستمارة من 20 عبارة تقيس محورين كما يلي : لالابناء 


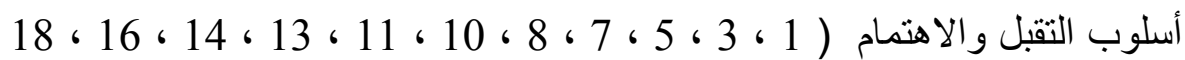

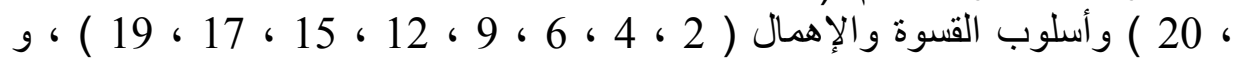

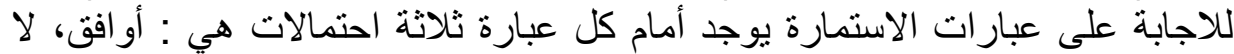

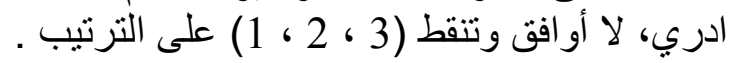

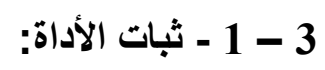

تم حساب ثبات الأداة باستخدام طريقتين : التطبيق وإعادة التطبيق و كان التبات

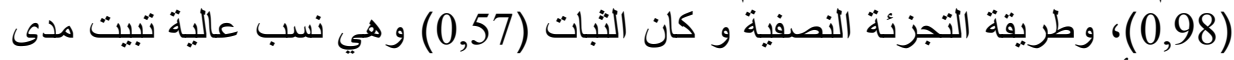

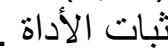

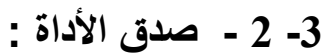

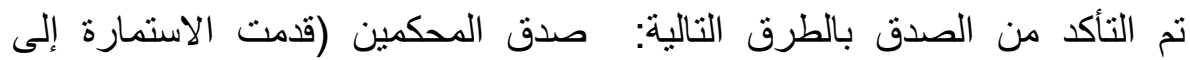

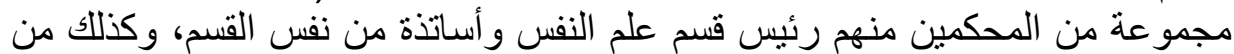

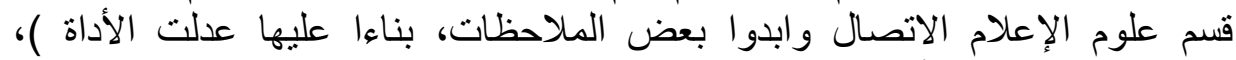

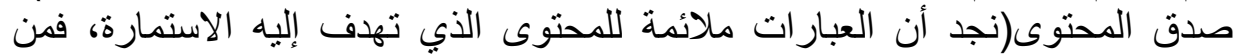

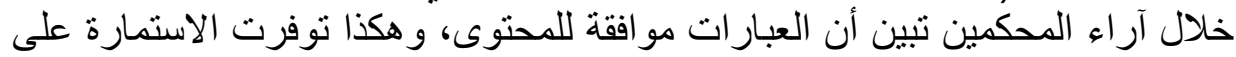

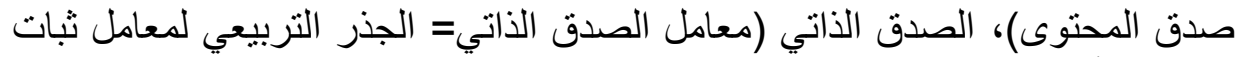

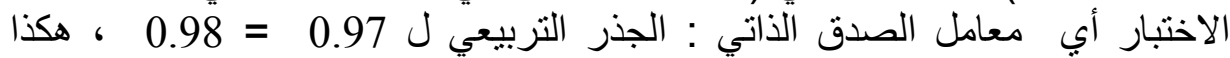

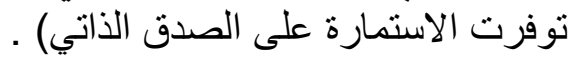

\section{4 - أساليب التحليل الإحصائي :}

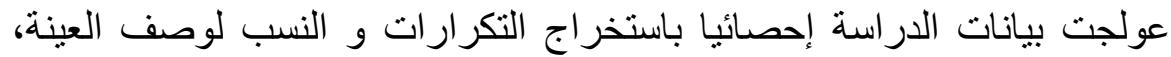

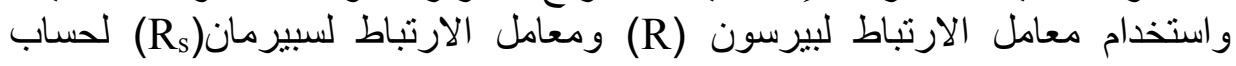

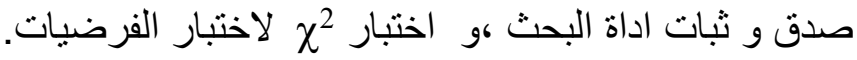

\section{5 - عرض ومناقشة نتائج الدراسة الميإنية :}

$$
\text { نتائج الفرضية الأولى : }
$$

جدول رقم (1): يوضح التكر ارات المشاهدة و التكر ارات المتوقعة لعينتي الطلبة

\begin{tabular}{|c|c|c|c|c|c|}
\hline \multicolumn{6}{|c|}{ المتميزة بالتقبل و الاهتمام. } \\
\hline الهامشموع & $\mathrm{N}=60$ ن & عينة الطلب & $\begin{array}{r}\text { المتفوقين } \\
\text { N }\end{array}$ & عينة الطلب & قم العبارة \\
\hline للسطور & التكرار & التكرار & تكرار متوقع & تكرار مشاهد & \\
\hline
\end{tabular}

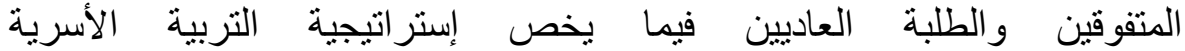




\begin{tabular}{|c|c|c|c|c|c|}
\hline & المتوقع (Fe) & المشـاهد & $\left(F_{e}\right)$ & $\left(F_{0}\right)$ & \\
\hline 351 & 173,68 & 174 & 177,31 & 177 & 1 \\
\hline 350 & 173,19 & 170 & 176,81 & 180 & 3 \\
\hline 321 & 158,84 & 157 & 162,16 & 164 & 5 \\
\hline 341 & 168,74 & 171 & 172,16 & 170 & 7 \\
\hline 346 & 171,21 & 171 & 174,79 & 175 & 8 \\
\hline 314 & 155,37 & 152 & 158,62 & 162 & 10 \\
\hline 347 & 171,70 & 172 & 175,29 & 175 & 11 \\
\hline 351 & 173,68 & 175 & 177,31 & 176 & 13 \\
\hline 333 & 164,78 & 166 & 168,22 & 167 & 14 \\
\hline 343 & 169,72 & 168 & 173,27 & 175 & 16 \\
\hline 327 & 161,81 & 164 & 165,19 & 163 & 18 \\
\hline 336 & 166,26 & 169 & 169,74 & 167 & 20 \\
\hline 4060 & & 2009 & & 2051 & المجموع \\
\hline
\end{tabular}

بعد حساب قيمة ${ }^{2}=18,58$ ،يلاحظ أن قيمة $\chi_{C}^{2}$ أكبر من قيمة $\chi_{T}^{2}$ (المجدولة)

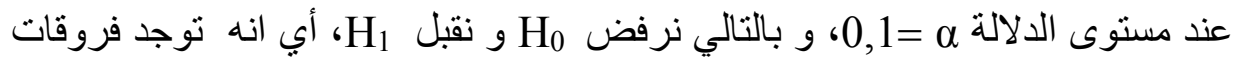

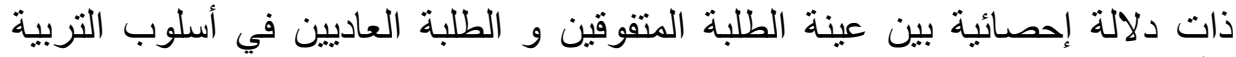

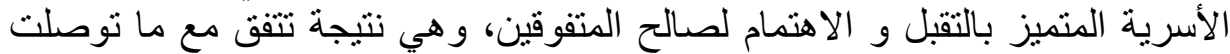

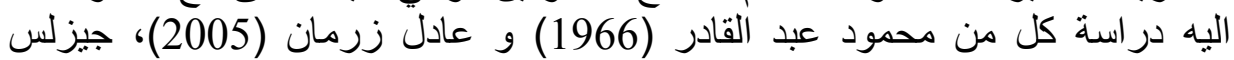
وجاكسون (Jizless et Jakson) ، تيرمان (Terman). نتائج الفرضية الثانية:

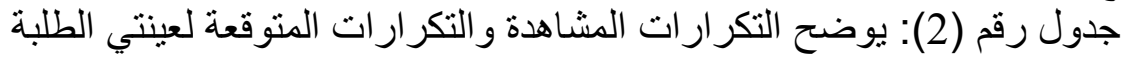

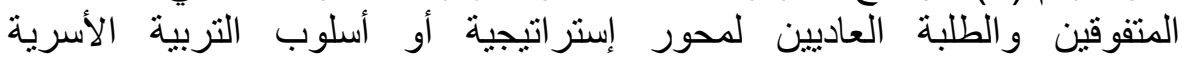

\begin{tabular}{|c|c|c|c|c|c|}
\hline \multirow{2}{*}{ اللهامشي } & \multicolumn{2}{|c|}{ عينة الطلبة العاديين N=60 } & \multicolumn{2}{|c|}{ عينة الطلبة المتفوقين } & \multirow[t]{2}{*}{ رقم العبارة } \\
\hline & التكرار & التكرار & تكرار & تكرار مشاهد & \\
\hline
\end{tabular}




\begin{tabular}{|c|c|c|c|c|c|}
\hline & المتوقع (Fe) & $\begin{array}{c}\text { المشاهد } \\
\text { (Fo) }\end{array}$ & $\begin{array}{l}\text { متوقع }\left(F_{e}\right) \\
\text { (2) }\end{array}$ & $\left(\mathbf{F}_{\mathbf{0}}\right)$ & \\
\hline 146 & 75,08 & 77 & 70,92 & 69 & 2 \\
\hline 131 & 67,37 & 66 & 63,63 & 65 & 4 \\
\hline 136 & 69,94 & 70 & 66,06 & 66 & 6 \\
\hline 170 & 87,42 & 86 & 82,57 & 84 & 9 \\
\hline 190 & 97,71 & 103 & 92,29 & 87 & 12 \\
\hline 133 & 68,4 & 69 & 64,60 & 64 & 15 \\
\hline 133 & 68,4 & 67 & 64,60 & 66 & 17 \\
\hline 153 & 78,68 & 75 & 74,32 & 78 & 19 \\
\hline 1192 & & 613 & & 579 & المجموع \\
\hline
\end{tabular}

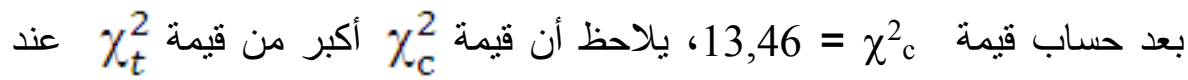

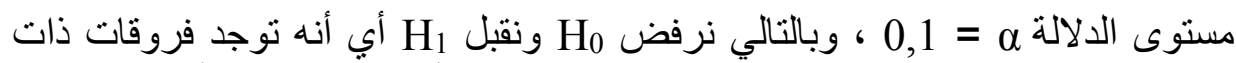

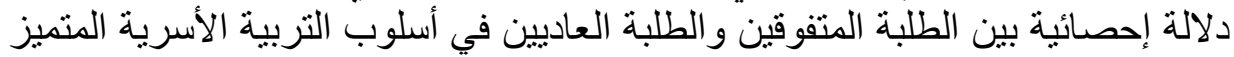
بالقسوة والإهمال لصالح العاديين، و هذا ما يشير إليه بلّوك الكئه (Block) (1971).

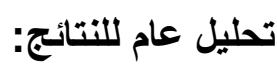

خلصت هذه الدراسة إلى أن الأبناء المتفوقين يتلقون تربية أسرية تتميز بالتقبل

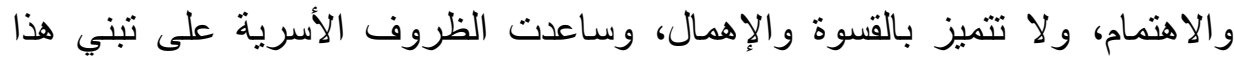

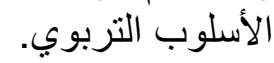
يتميز أولياء الطلبة المتفوقين بارتفاع مستواهم التعليمي، فحوالي 75 \% 76 \% من الآباء

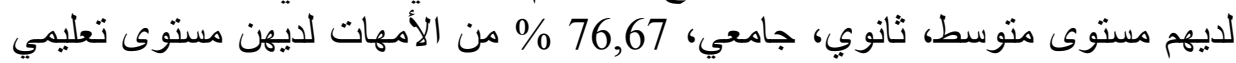
من الابتدائي فما فوق.

يشتغل أولياء المتفوقين المهن ذات الأجر الكبير، بنسبة 60 \% للآباء و 8,33 \% للأمهات. - أما الر اتب الثهري فلا يؤثر على تفوق الأبناء الدراسي. 
- كما يسود اسر المتفوقين حالات الزواج بنسبة 96,66 \% . .

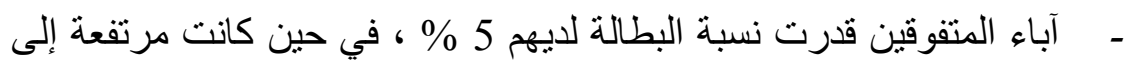
83,33 \% \% لدى الأمهات.

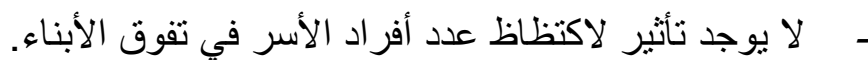

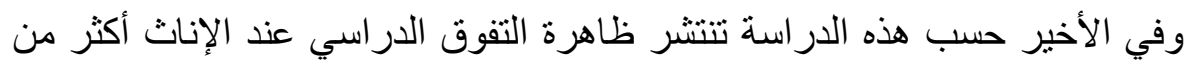

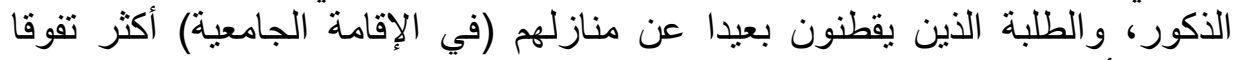

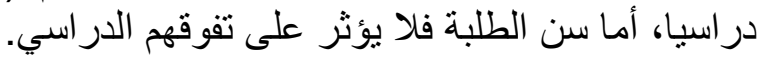

يمكن تصنيف ما توصلت إليه الدراسات عن دور الأسرة في تفوق الأبناء الدراسي لئي

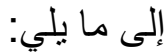

\section{1 - الانسجام بين الوالاين:}

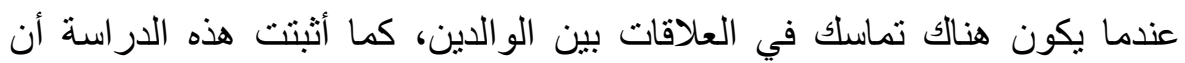

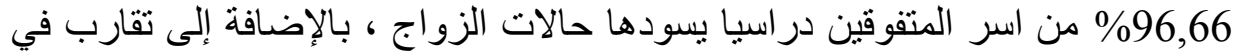

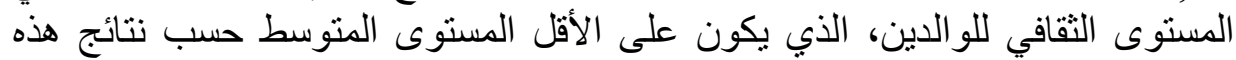

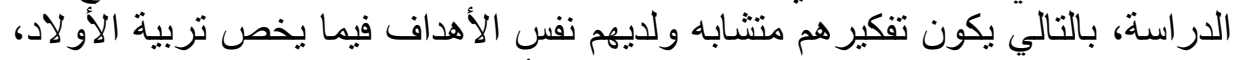

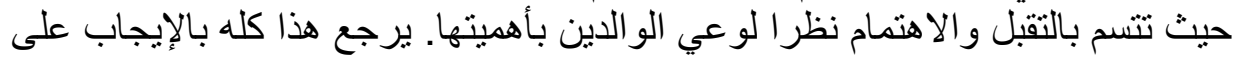

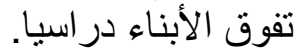

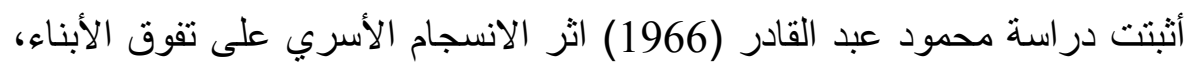

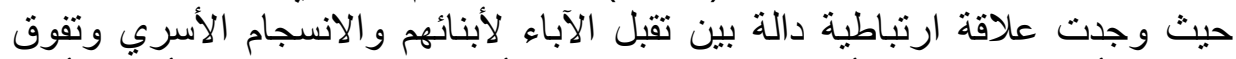

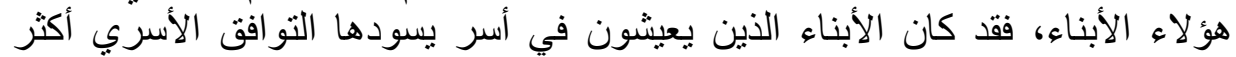

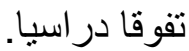

\section{2- الانسجام بين الوالدين والأبناء:}

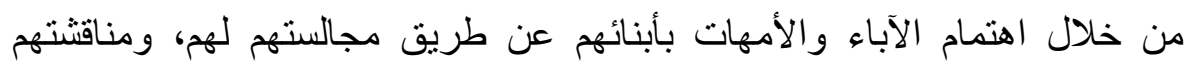

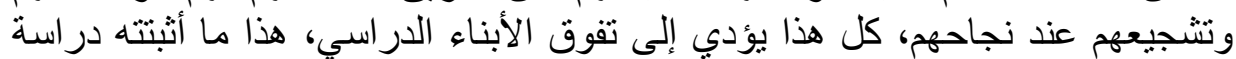
عادل زرمان (2005).

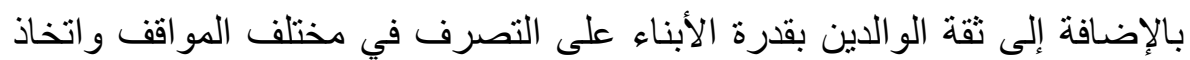

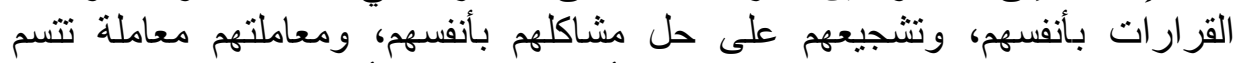
بالتسامح بدرجة مناسبة، فهذا يسهل على الأبناء التعبير عن أفكار هم وينمي لديهم الثقة في النفس.

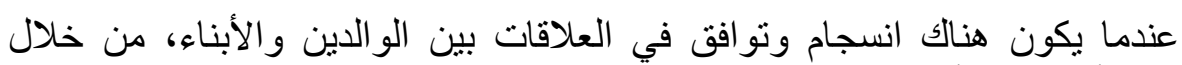

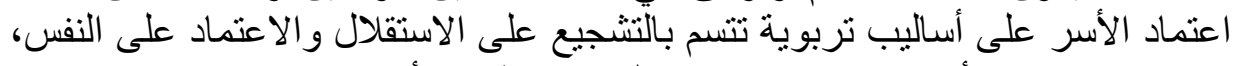
واحتر ام رغبات الأبناء ومحبتهم ومنحهم التقدير، يظهر الأبناء تفوقا في دراستهم. 
إن عطف الوالدين على الأبناء وتضاؤل العقاب ينمي مهاراتهم العقلية وبالتالي

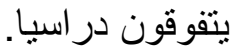

3- اهتمام الوالدين بالجانب الفكري للأبناء:

يرى جيزلس وجاكسون (Jizless et Jackson) أن آباء التلاميذ المتفوقين كانوا أكثر

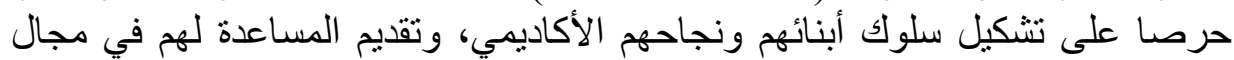
الأداء الدراسي ودرجة اهتمامهم بالأداء الدراسي. بالإضافة إلى تركيز الآباء اهتمامهم على الثقافة والخلق الطيب و الاجتهاد و الانفتاح

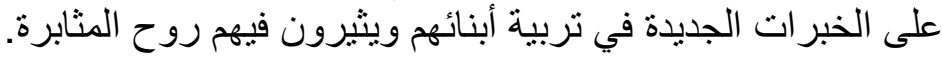

4- - توفير الوسائل المثقفة:

يؤكد تيرمان (Terman) أن اسر المتفوقين لديهم مكتبات لا يقل متوسط عدد الكتب إنباء

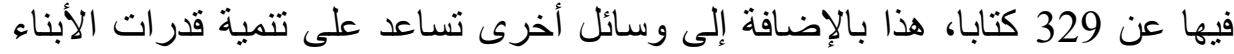

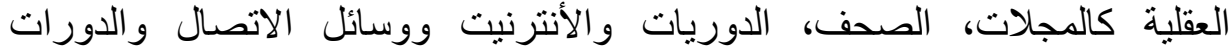

التنقيفية.

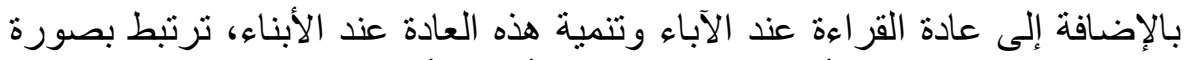

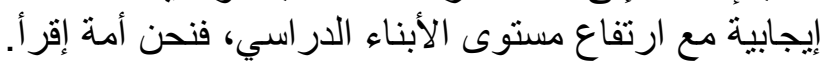

5- تجب التسلط واللامبالاة:

يرى دورنبيش ومساعدوه أن الأسر التي تتبنى أسلوب القسوة و الإهمال تكون نتائج

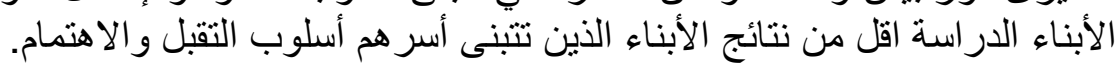
فالمعاملة القاسية والتلفظ بألفاظ جارحة وسيئة تؤثر سلبا على التحصبل، فالأبناء

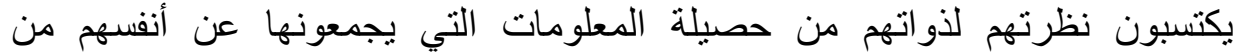

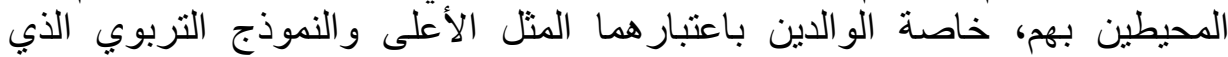

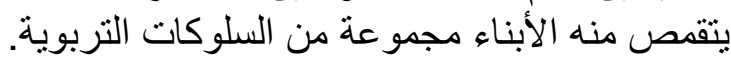
يشير بلوك (Block) (1971) أن الأسر التي تتبنى أسلوب الإهمال، يظهر أبنائها اضطرابات في علاقاتهم مع زملائهم ولا يتفاعلون معهم، ولا ليهتمون بدراستهم، وتنخفض درجاتهم وتحصيلهم.

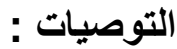
من خلال نتائج الدر اسة توجه الباحثة توصيات إلى 3 جهات كالتالي: 1 ) المؤسسات التربوية:

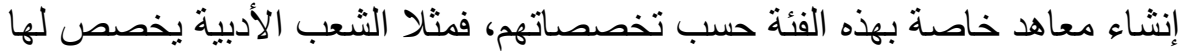
معهد يضم كل التخصصات التي يدرسونها، ونفس الثيء بالنسبة للثعب العلمية، مع فئل 
تجهيز هذه المعاهد بالوسائل المتطورة التي تخدم تخصصاتهم، ومواكبة التطور الذي لإي

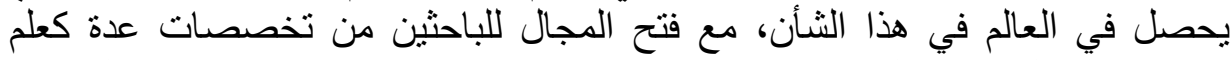

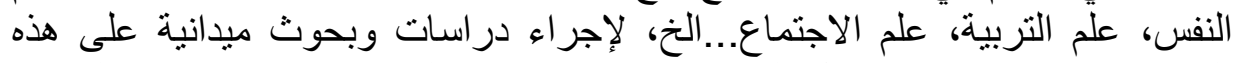

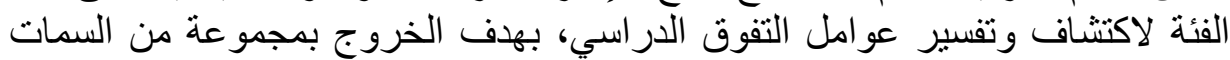

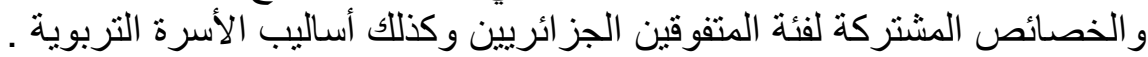

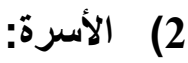

على الوالدين توفير مختلف الوسائل الثقافية بقدر ما تسمح به إمكاناتهم، فالمكتبة

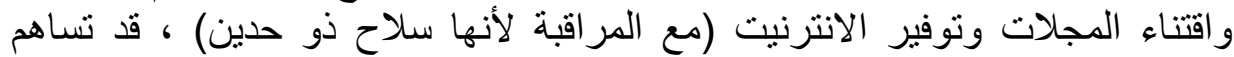

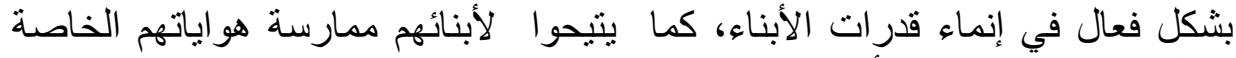

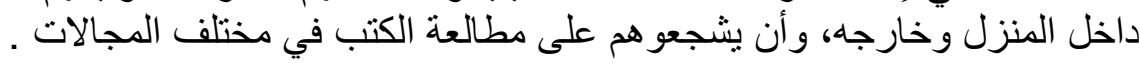

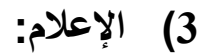

ينبغي أن تكون هناك برامج توجيهية في البلاد العربية وخاصة الجزائر، تهنم

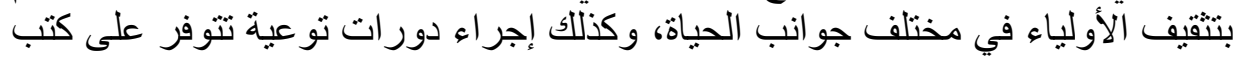
ومجلات تثري ثقافة الأسرة على الأخص ما يتصل بطريقة التعامل مع أبنائهم

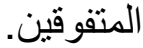

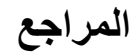

1. المعايطة خليل عبد الرحمان، البواليز محمد عبد السلام: الموهبة والتفوق، دار الفكر

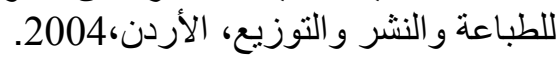

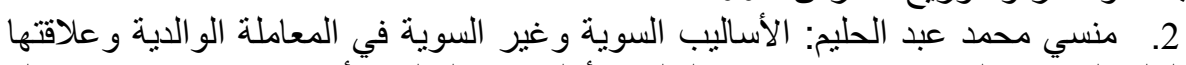

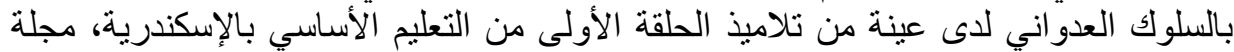

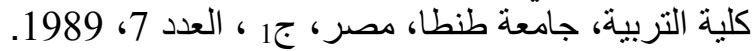

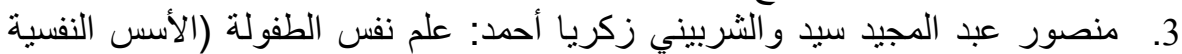

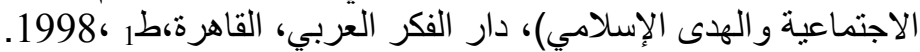

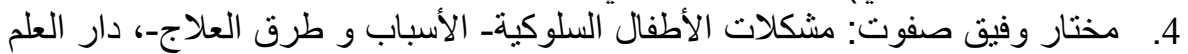
و الثقافة، القاهرة، طر، 1999.

5. 6 - غالب مصطفى: سيكولوجية الطفولة والمراهقة، مكتبة الهلال، بيروت، طه، 
6. عفيفي عبد الخالق محمد: الخدمة الاجتماعية المعاصرة ومشكلات الأسرة و الطفولة، مكتبة عين شمس، القاهرة، 1999. 7. الأمة للطباعة والنشر و التوزيع، الجزائر،طئ ، 2003.

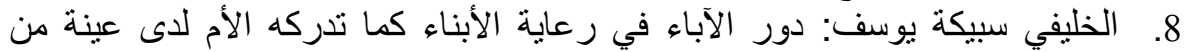

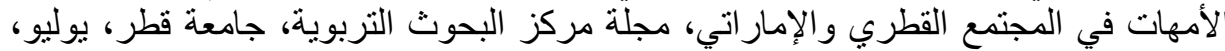

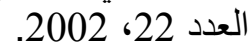

9. إسماعيل محمد عماد الدين وآخرون: كيف نربي أطفالنا ـ التنشئة الاجتماعية للطفل في الأسرة العربية ـ دار النهضة العربية، القاهرة، طح ، 1974.

10. الطواب سيد محمود: النمو الإنساني- أسسه وتطبيقاته ـ ، دار المعرفة الجامعية

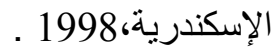

11. الأخرس محمد صفوح : تركيب العائلة العربية ووظائفها ـ در اسة ميدانية لو اقع العائلة

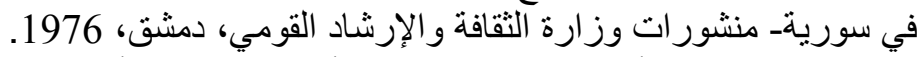

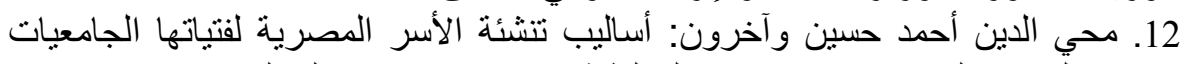

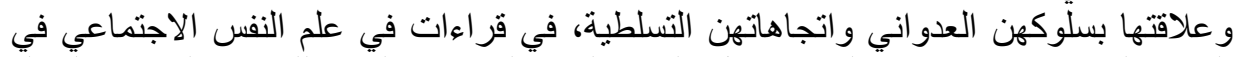
الوطن العربي، إعداد وتقديم لويس كامل مليكة، الهيئة المصرية العامة الهية للكتاب، القاهرة، المجلد . 2 1985، 4

13. عكاثنة محمود فتحي: علم النفس الاجتماعي، مطبعة الجمهورية، الإسكندرية،د س.

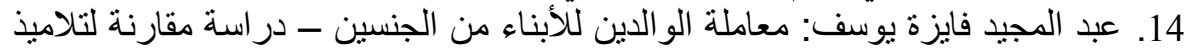

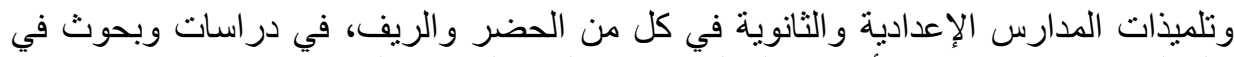
علم النفس، إعداد نخبة من أساتذة علم النفس، دار الفية الفكر العربي، القاهرة، 1995.

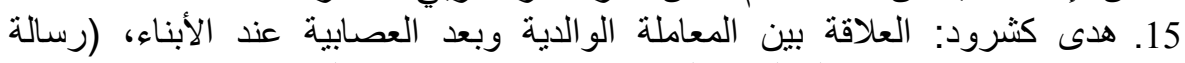

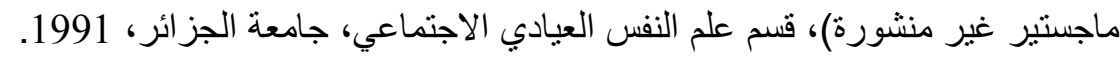

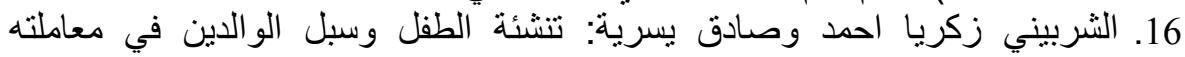

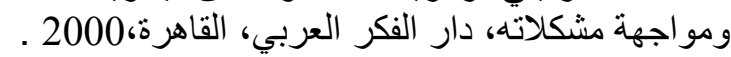

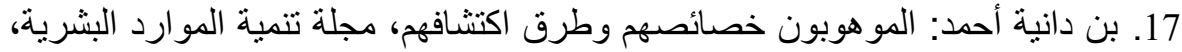
جامعة سطيف، دار الهدى للطباعة والنشر و التوزيع، عين مليلة ،2006.

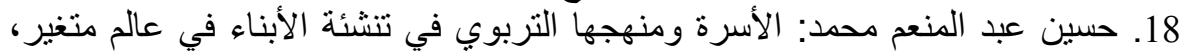
مكتبة النهضة، القاهرة، دس. 19. إبراهيم مجدي عزيزة الاهرة دوسوعة التنريس، دار المسيرة للنشر والتوزيع والطباعة،

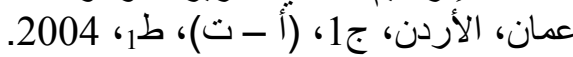

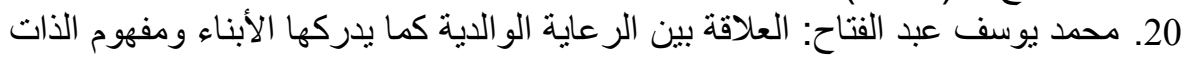

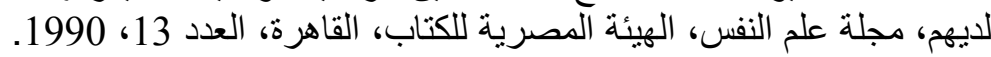

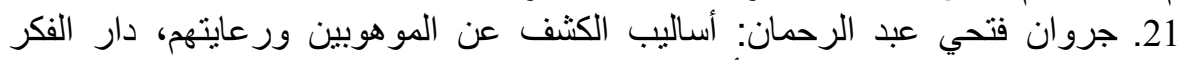

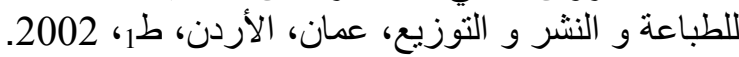
22. عكاثة محمود فتحي: علم النفس الاجتماعي، مطبعة الجمهورية، الإسكندرية،د س. 


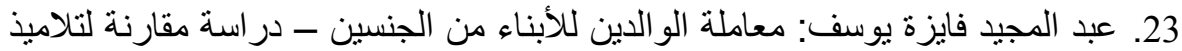

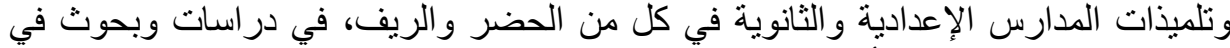

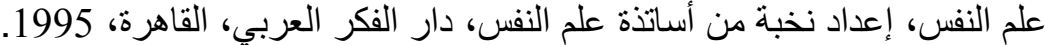

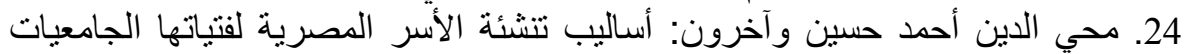

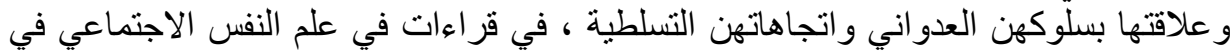

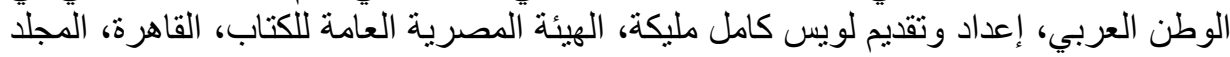
1985، 4

25. الأخرس محمد صفوح: تركيب العائلة العربية ووظائفها - در اسة ميدانية لو اقع العائلة في سورية- منشور ات وزارة الثقافة والإرشاد القومي، دمشق، الإنة 1976.

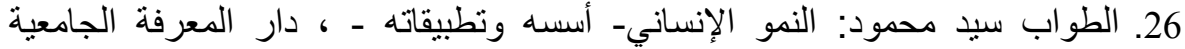

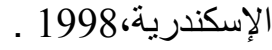

27. إسماعيل محمد عماد الدين وآخرون: كيف نربي أطفالنا ـ التنشئة الاجتماعية للطفل

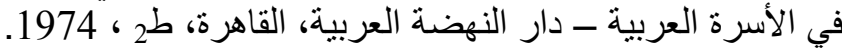
28. مختار وفيق صفوت: مشكلات الأطفال السلوكيةـ الأسباب وطرق العابة العاج-، دار العلم

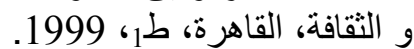
29. منصور عبد المجيد سيد والثربيني الإبيدي زكريا أحمد: علم نفس الطفولة (الأسس النفسية

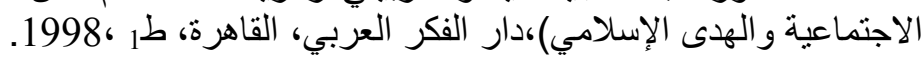

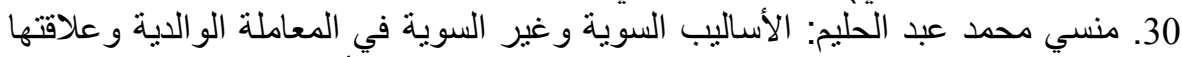

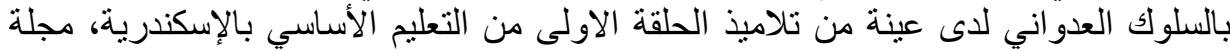

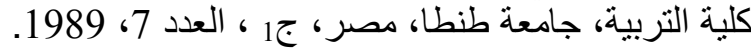
31. المعايطة خليل عبد الرحمان، البواليز محمد عبد السلام: الموهبة والتونة التفوق، دار الفكر

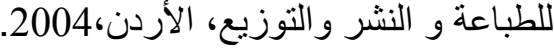

32 - Helen Bee : psychologie du développement : les âges de la vie, de Boeck, université, Bruxelles, Paris, 1997. 